\title{
ACTIVITY BASED COSTING - A TOOL OF ACCURATE COSTING
}

\author{
CMA Nishith Parikh \\ Research Scholar \\ Rai University, Dholka. \\ Dr. Gurudutta P. Japee \\ Asso. Prof. Gujarat University \\ Ahmedabad
}

\begin{abstract}
Activity based costing is a system of allocating overheads to jobs, processes or products on the basis of activities responsible for such expenses, instead of the traditional system, so that true and logical cost is obtained. According to traditional system, firstly the overheads are apportioned over various departments on some basis and then they are absorbed to the individual product on the basis of direct wages or direct labour hours or direct machine hours etc. Suppose factory overheads are absorbed on the basis of machine hours, this is not logical, because all factory overheads are not dependent on machine hours and so the overheads allocated are incorrect and consequently the total cost and selling price based on such costs are all incorrect and illogical, which may put business into trouble. The overheads are absorbed under Activity Based Costing on the basis of activities giving rise to overheads, e.g. to allocate the expenses of procurement of goods, it can be divided into three activities like placing an order, receipts and inspection, storage etc. The total overheads of all three activities are ascertained and are absorbed to various jobs, processes or products in proportion to the services which they received from these activities, e.g. the inspection cost is absorbed on the basis of number of times the product is inspected, cost of placing an order is allocated on the basis of number of times the orders were placed etc.
\end{abstract}

\section{Introduction}

Activity Based Costing (ABC) seeks to identify more accurate costing attributed to goods sold, this can lead to pricing which better reflects the true cost - so may lead to better efficiency and profit margins. However, it is more complex.

Traditional absorption costing divides indirect costs across all goods sold based only on volume, it does not consider that some goods may use more of the firm's resources than others, and thus incur more cost.

$\mathrm{ABC}$ captures the costs of goods by creating cost pools, and identifying cost drivers, for different activities. The cost of these activities is then divided between the goods that go through them. For example, consider a factory where two different goods are produced in equal quantities and both go to the same packaging department, but one is packaged by a machine which uses twice as much electricity and maintenance. In absorption costing the energy and maintenance costs would normally be totaled and considered indirect 
costs, leading to inaccurate cost attribution as one uses twice as much. In $A B C$ the activities would be tracked and costed separately, so that the higher cost of one machine can be attributed to the products that use it.

\section{- ABC IN SERVICE INDUSTRIES}

The need for reliable consistent strategic performance information is the main rationale for a service company to apply $A B C$ system as this information is the main drive for company's profitability and competitiveness. ABC is also considered a very useful decision making tool for economic analysis in service sectors, especially in the areas of planning and control. Cooper and Kaplan asserted that service firms can benefit from using $\mathrm{ABC}$ as they have the same set of issues as manufactures as the analysis of operating expenses and the performance of service activities that demand resources. They further noted that it is also an effective tool in service firms for tracing cost to services produced and implementing total quality thinking in service firms. It also motivates management and helps in analyzing activities and determining their value to the customers

\section{- CONCEPT OF ACTIVITY-BASED-COSTING}

An organization performs activities to do its business. These activities define the kind of business you are in: a ship owner has an activity to unpack boats; an accounting firm prepares tax returns; a manufacturer produces products; a council delivers services; a university teaches students. All activities consume resources. It is the consumption of these resources that adds to overhead costs.

The basis of Activity Based Costing is look at the activities required to produce the cost of the product or service. The activities consume resources and the 5 cost of these can be calculated. The amount of activity required for each product and service is determined, hence the real cost can be determined.

\section{- WHAT'S WHAT IN ABC?}

- The activity is the work that is done.

- The resource is what the activity uses to do the work e.g. people, equipment, and services. Resources cost money.

- The cost of the activity depends on the quantity of resources used to accomplish the activity.

- The cost driver for an activity is the factor that influences the amount of the resources that will be consumed by this activity.

Example: the activity is delivering goods. The costs of this activity include the truck drivers' wages, fuel, depreciation of the truck, insurance, etc. The quantities of the resources that will be consumed by this activity are influenced by the number of deliveries made per year. Hence the cost driver could be the number of deliveries. A cost driver is designed to allocate the delivery activity cost pool to the cost objects. 
- The activity driver measures how much of the activity is used by the cost object. Example: Product A is delivered once a month, whereas product B is delivered once a week. Products $A$ and $B$ require a different number of deliveries, hence the cost of the delivery activity should be assigned to each product on the basis of the number of deliveries each uses.

- The cost object is whatever it is you wish to cost. It could be a product, service, process, job or customer.

While traditional costing arbitrarily allocates overhead costs, $A B C$ traces overhead costs by looking at the activities that each product and service calls upon. With $A B C$ the products consume the activities. It is the activities that cost money.

\section{- WHY USE ACTIVITY-BASED-COSTING?}

Activity-Based-Costing is necessary for the following reasons.

- Understand true profitability of your customers, products, or services

- Quantify the cost of non-value added activities such as errors and reworks

- Identify opportunities to reduce costs and/or increase efficiency

- Obtain actionable information to negotiate price increases for unprofitable clients

- Stratify overhead costs so they can be managed more effectively.

\section{CONCLUSION}

The concept of activity based costing aims to decide accurate cost through activity based costing system with the help of cost drivers instead of traditional system of costing. Activity based costing was evolved with specific objectives of accurate cost and within a particular short time period, activity based costing has succeeded in becoming a popular cost accounting system. But, in India, the rate of adoption of activity based costing is very limited and is not popular as in other countries. Activity based costing techniques helped to companies in determine accurate product or service cost. Activity based costing provided information regarding processes that should be improved and the products or services that are contributing the most to company's profitability. Activities based costing also helped in knowing what are the factors that contribute most to cost, which in turn assisted management in choosing best alternative in reducing overall cost incurred by the company. Activity based costing can be best system to be utilized in implementing accounting at the initial level. This has made the entire concept more dynamic as cost reduction or control or both and process improvement decisions can be more effectively implemented with the use of activity based costing system.

\section{REFERENCES:}

1. Clarke P, Mullins T (2001). Activity Based Costing In The Non- Manufacturing Sector In Ireland: A Preliminary Investigation. Irish. J. Manage, 22(2): 1.

2. Cooper, R. and Kaplan, R.S. (1997) Cost \& Effect: Using Integrated Cost Systems to Drive Profitability and Performance. Boston: Harvard Business School Press. 
3. Cooper, R., \& Kaplan, R. S. (1992, September). Activity-Based Systems: Measuring the Costs of Resource Usage. Accounting Horizons, 6(3), 1-13.

4. Odysseas Pavlatos: - Journal of Hospitality \& Tourism Research, Vol. 33, No. 4, pp. 511527,2009

5. Abdul Adamu: - Department of Business Administration, Nasarawa State University, Keffi - Nasarawa State, Nigeria 